
FUNÇÕES ORGÂNICAS NO ENSINO DE QUÍMICA

\title{
COSMETICS AS THEMATIC TO APPROACH ORGANIC FUNCTIONS IN CHEMISTRY TEACHING
}

\author{
FREITAS, Tasielle Lima ${ }^{1 *}$; DA COSTA, Maria Aparecida ${ }^{1}$; FREITAS, Fabricia Carla Ribeiro Mendes ${ }^{1}$; OLIVEIRA, \\ Tatiana de Fátima'; MORAES, Lilian Marciolina'; FIELD'S, Karla Amâncio Pinto'; REZENDE, Gláucia Aparecida \\ Andrade ${ }^{1}$; SANTOS, Renato Gomes ${ }^{2}$. \\ ${ }^{1}$ Instituto Federal de Educação, Ciência e Tecnologia de Goiás (IFG), campus Itumbiara-GO, Av. Furnas, 55, \\ cep 75524-010, Itumbiara - GO, Brasil (fone: +55 64 21035600) \\ ${ }^{2}$ Centro de Ciências Exatas e Tecnológicas, Universidade Estadual de Goiás (UEG), campus Henrique Santillo, \\ Anápolis, Br 153, №3105 Fazenda Barreiro do Meio, Caixa Postal 459 cep 75132-400. Anápolis - GO \\ ${ }^{*}$ Autorcorrespondente \\ e-mail: tasielle@hotmail.com
}

Received 15 November 2015; received in revised form 7 December 2015; accepted 8 January 2016

\section{RESUMO}

O ensino de ciências tem se tornado cada dia mais complexo quanto a sua abordagem na tentativa de promover uma aprendizagem mais efetiva dos conteúdos, fato que exige do professor reflexão quanto à sua prática docente, buscando a utilização de diferentes estratégias de ensino, como a abordagem de conteúdos químicos por meio da relação destes com algum contexto social em que encontram-se inseridos, por exemplo, o uso dos cosméticos. O presente trabalho relata sobre um projeto de intervenção pedagógica na disciplina de Estágio Supervisionado Etapa IV, que buscou, a partir da temática "cosméticos", trabalhar o conteúdo de funções orgânicas. O trabalho foi desenvolvido em forma de minicurso, durante dois encontros de quatro horas, para alunos da terceira série do Ensino Médio do curso técnico integrado em química do campus ItumbiaraGO. No primeiro encontro fez-se uso de um questionário, leitura e reflexão de dois textos, ambos inerentes à temática. O segundo versou sobre a identificação das funções orgânicas e suas relações com os cosméticos. Ao término do minicurso, percebeu-se que ao correlacionar temas que fazem parte do cotidiano dos alunos com conteúdos químicos, estes sentem-se mais envolvidos e motivados pela Química, pois compreendem a importância e aplicabilidade desta ciência.

Palavras-chave: Ensino de ciências, Aprendizagem efetiva, Contexto social.

\section{ABSTRACT}

The science teaching has become more complex each passing day regarding its approach in an attempt to promote a more effective content learning, what requires from the teachers reflection concerning their education teaching, aiming at the use of different teaching strategies, such as the approach of chemistry contents through their relation to a social context in which they are inserted, as the use of cosmetics. This paper reports on a pedagogical intervention project in the subject of Supervised Stage IV, which aimed at teaching the chemistry content of organic functions by means of the "cosmetics" thematic. This work was carried out in the form of a minicourse, during two meetings, for students of the Third year of high school in an integrated technical course in chemistry in Itumbiara-GO. In the first meeting it was made use of a questionnaire and two texts, both regarding the thematic. The second meeting dealt with the organic functions identification and their relation to the cosmetics. At the end of the minicourse it was noted that by correlating themes that are part of students' everyday life to Chemistry, they feel more involved and motivated by Chemistry subject, because they can understand its importance and applicability.

Keywords: Science Teaching, Effective learning, Social Context. 


\section{INTRODUÇÃO}

Muito é discutido sobre o processo de ensino e aprendizagem das Ciências da Natureza, dentre essas discussões destaca-se a atribuição a estas ciências como sendo chatas, burocráticas e baseadas na "decoreba". Tais fatos acentuam-se ainda mais no Ensino Médio, no qual atribuem-se aos conteúdos das disciplinas de Química, Física e Biologia como de difícil compreensão, distante dos interesses dos alunos, descontextualizadas e, para alguns, "sem utilidade alguma" (SCARPA et al., 2014).

Sendo assim, pode-se inferir que embora o currículo do Ensino Médio esteja passando por mudanças, este ainda não está pautado na formação integral do aluno, mas sim em abordagens propedêuticas e não contextualizadas, as quais se dissociam da realidade na qual os alunos encontram-se inseridos (SILVA e SIMÕES, 2013).

Por sua vez, Gilbert (2006) defende que o ensino de química tem enfrentado vários tipos de problemas inter-relacionados, sendo eles: carga excessiva de conteúdo, abordagens de fatos isolados, falta de transferência de conhecimento que possa ser aplicado ao cotidiano, falta de relevância e ênfase inadequada dos conteúdos e conceitos.

Nesse sentido, faz-se necessário ressaltar que o ensino das Ciências da Natureza, especialmente no que se refere ao ensino de Química, deve buscar trabalhar de forma a atender aos objetivos de ensino propostos pelas diretrizes do Ensino Médio, ou seja, promovendo a interdisciplinaridade e a contextualização dos conteúdos por meio da abordagem de situações reais provenientes do cotidiano (BRASIL, 2006).

No que tange à contextualização, os PCNEM (Parâmetros Curriculares Nacionais para o Ensino Médio) propõem que ao se trabalhar determinado conteúdo, este seja abordado de maneira contextualizada, pois a contextualização é um importante recurso para retirar o aluno da condição de espectador passivo e, assim, tornar a aprendizagem mais efetiva, visto que a associa com experiências da vida cotidiana ou com os conhecimentos adquiridos empiricamente (BRASIL, 1999).

Ressalta-se, entretanto, que os contextos a serem trabalhados devem ser capazes de propiciar aos alunos uma base necessária para que estes possam associar de forma coerente os conteúdos e conceitos já estudados com aqueles que ainda serão abordados (GILBERT, 2006).

Com relação à interdisciplinaridade, Sá e Silva (2008) afirmam que a abordagem de conceitos químicos relacionada ao cotidiano dos alunos e com a interdisciplinaridade é um mecanismo promissor de uma aprendizagem ativa e significativa, pois na prática pedagógica a contextualização e a interdisciplinaridade "alimentam-se" mutuamente. Para se trabalhar essa relação de maneira produtiva, os PCNEM (BRASIL, 1999) sugerem a utilização de temas sociais para contextualização do conhecimento químico e estabelecimento de inter-relações deste com os vários campos da ciência.

Ainda, segundo Morillo et al., (2002) o uso da interdisciplinaridade tem se mostrado bastante proveitoso e reconhecido, visto que associa-se à criatividade, progresso e inovação. Principalmente devido ao fato de que muitos avanços contemporâneos da ciência devem-se às inter-relações de diferentes áreas do conhecimento.

Embasado no que fora supracitado, dentre as maneiras de se alcançar tais objetivos destaca-se a utilização de temas que promovam relações entre o currículo adotado e o cotidiano dos alunos. Desta maneira, proporcionado aos mesmos relacionar os conteúdos abordados em sala com suas aplicações práticas na sociedade como um todo, facilitando, portanto, a internalização dos conhecimentos químicos (BRASIL, 1999). Processo esse denominado contextualização, que segundo Silva (2003), é um recurso para aproximação e/ou inter-relação entre os conhecimentos escolares e fatos e/ou situações presentes do dia a dia dos alunos. Em suma, seria problematizar, investigar e interpretar situações cotidianas por meio dos conhecimentos adquiridos, tais como os químicos, ou seja, seria reconstruir/ressignificar o conhecimento (BRASIL, 1999).

Para Santos et al. (2004), a abordagem de temas deve ser desenvolvida de forma a possibilitar ao aluno a compreensão dos processos químicos envolvidos e discussão das aplicações tecnológicas relacionadas ao tema trabalhado, compreendendo, deste modo, os efeitos das tecnologias na sociedade, na 
melhoria da qualidade de vida das pessoas e nas suas decorrências ambientais.

Em consonância com Santos et al. (2004), Bennett e Holman (2002) enfatizam o quanto a utilização de contextos/temas e aplicações da química tem sido utilizados nas últimas décadas para desenvolver princípios químicos, sendo estes, por exemplo, por meio de inclusões sociais, econômicas, aplicações ambientais, industriais e tecnológicas desta ciência.

Dentre os temas inseridos nos contextos sociais, destacam-se os cosméticos, que embora ainda não conhecidos por esse nome, eram utilizados pelos povos antigos com o intuito de aromatizar e adornar os corpos (SCHUELLER, 2001). De acordo com Barata (1995), pode-se definir o termo "cosméticos", como sendo substâncias e/ou preparados cuja aplicação se dá em contato com as partes superficiais do corpo, apresentando como funções específicas limpá-lo, perfumá-lo ou protege-lo. Porém, estes, por sua vez, não apresentam fins terapêuticos.

Tendo em vista que um dos principais objetivos do ensino de ciências é a atribuição de maior relevância aos conteúdos estudados (Stuckey et al., 2013), a utilização dos cosméticos como tema gerador de conhecimento químico apresenta-se como uma possibilidade promissora de contextualização de abordagens conceituais da disciplina de Química no Ensino Médio, pois viabiliza o entendimento dos alunos sobre as aplicações científicas em vários setores da sociedade, nesse caso, o setor relacionado ao cuidado corporal.

Em face ao exposto, buscou-se desenvolver no ensino de Química uma aprendizagem efetiva dos alunos por meio da contextualização e relação do conteúdo de funções orgânicas com a temática do uso dos cosméticos, uma vez que para fabricá-los faz-se uso de substâncias químicas que apresentam várias funções orgânicas, as quais podem ser, por intermédio da elucidação e análise de suas fórmulas estruturais, estudadas e identificadas.

\section{DESENVOLVIMENTO}

O presente trabalho trata-se de relato de experiência desenvolvido como projeto de intervenção pedagógica na disciplina de Estágio Supervisionado Etapa IV ofertado no $8^{\circ}$ período do curso de licenciatura em Química do IFG (Instituto Federal de Educação, Ciência e Tecnologia de Goiás), campus Itumbiara.

Como estratégia didática a referida proposta foi realizada em forma de minicurso devido ao fato deste permitir se trabalhar abordagens em um tempo disponível maior que o convencional (GOMES et al., 2014). Ademais, o desenvolvimento desta estratégia baseou-se nos três momentos Pedagógicos propostos por Delizoicov e Angotti (1990), que são: Problematização Inicial, Organização do Conhecimento e Aplicação do Conhecimento.

Em relação ao minicurso, este foi realizado em novembro de 2014 mediante a temática do uso dos cosméticos e contou com a participação de vinte alunos da terceira série do Ensino Médio do curso técnico integrado em química do próprio campus, tendo o mesmo duração de oito horas, sendo estas divididas em dois encontros de 4 horas cada. A seguir, encontram-se as etapas do desenvolvimento de cada encontro.

\subsection{Primeiro Encontro}

Em um primeiro momento (Problematização inicial) foi exposto aos alunos que o conteúdo de funções orgânicas seria trabalhado pautado do tema cosméticos, e por isso, solicitou-se aos alunos que respondessem a um questionário, cujo intuito foi de verificar a concepção destes em relação ao conhecimento da temática a ser trabalhada, bem como sobre a relação intrínseca deste tema com os conceitos químicos e sua influência na sociedade. As questões contidas no questionário foram propostas pelos próprios autores e estão elucidadas no Quadro 1.

Quadro 1.Questionário aplicado aos alunos.

\begin{tabular}{l} 
Questionário - Questões \\
\hline O que são cosméticos para você? \\
Você utiliza algum cosmético no seu dia a dia? \\
Quais? \\
Considerando o que você entende por cos- \\
méticos, quais funções estes produtos apre- \\
sentam? \\
É possível aprender conceitos químicos a par- \\
tir dos cosméticos? Se sim, quais você consi- \\
dera possível? \\
Produtos cosméticos são importantes na sua \\
vida ou desnecessários?
\end{tabular}


Você já teve alergia com algum cosmético? Se sim, qual?

Fonte: Autoria.

Destaca-se que, segundo Chaer, Diniz e Ribeiro (2011), o uso de questionário é uma técnica bastante pertinente de ser utilizada, visto que permite tratar de questões/problemas empíricos que envolvam opinião, percepção, posicionamento e preferências dos pesquisados. Ainda, em relação ao uso de perguntas abertas, estas permitem que os sujeitos da pesquisa expressem o que vier em suas mentes, não havendo influência sobre suas respostas, como pode ocorrer ao se fazer uso de perguntas fechadas.

Após discussão das perguntas do questionário, foram entregues e debatidos dois textos inerentes à temática, o primeiro intitulado "A história dos cosméticos" e o segundo "Química dos cosméticos", ambos extraídos de Santos et al. (2013), páginas 103-104 e 130-134, respectivamente. Em relação ao último texto, este versava sobre a composição e uso de vários cosméticos, tais como perfumes, cremes hidratantes, desodorantes, pasta dental, xampus e condicionadores, sendo destacado, ao término do encontro, algumas das formas de uso e cuidados que se deve ter ao utilizar-se cosméticos.

\subsection{Segundo Encontro}

Este fez referência ao segundo momento proposto por Delizoicov e Angotti (1990), denominado Organização do conhecimento. Para tanto, a fim de se trabalhar o conteúdo de funções orgânicas, foi entregue aos alunos uma tabela, produzida pelos próprios autores, contendo as principais funções orgânicas estudadas na disciplina de Química (Tabela1).

Adicionalmente, a fim de correlacionar as funções orgânicas com os cosméticos, foram apresentadas as principais substâncias presentes nas formulações de vários cosméticos (Quadro 2), bem como suas fórmulas estruturais, que posteriormente subsidiariam o estudo e identificação das funções orgânicas inicialmente discutidas no início do encontro, dando início ao terceiro momento, Aplicação do Conhecimento.

Ao término, objetivando avaliar o aprendizado dos alunos, foi proposta uma lista de atividades sobre funções orgânicas adaptada da unidade 23, páginas 541 a 550, do livro de Química, volume único, de Usberco e Salvador (2002).

\section{RESULTADOS E DISCUSSÃO}

\subsection{Primeiro Encontro}

Em relação à primeira pergunta sobre o que seriam os cosméticos, ao analisar-se as respostas obtidas, constatou-se que de forma geral, os mesmos afirmavam que os cosméticos estariam relacionados apenas à higiene e estética/beleza. Para tanto, optou-se por representar tais respostas de forma simples por meio de um gráfico.

Ao analisar o referido gráfico, percebe-se que a metade dos alunos, $50 \%$, pensa que os cosméticos, na verdade, seriam estética, ou seja, estariam relacionados à estética, enquanto que $25 \%$ propuseram que os mesmos estariam relacionados à higiene e os outros $25 \%$ aos dois, estética e higiene. Tais inferências podem ser constatadas no Gráfico 1.

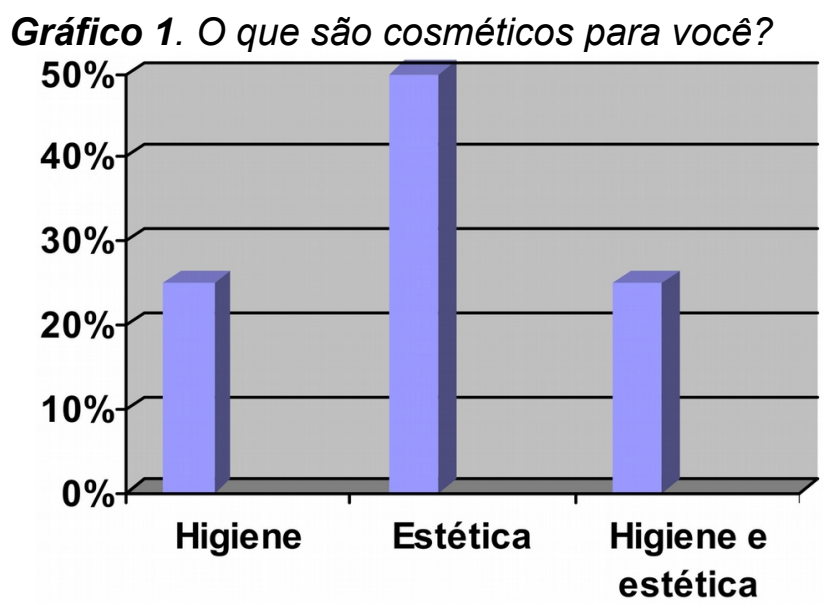

Fonte: Autoria.

Partindo-se das respostas dos alunos, a fim de complementá-las, aos mesmos foi apresentado a definição de cosmético proposta pela Câmara Técnica de Cosméticos (CATEC), órgão vinculado à Agência Nacional de Vigilância Sanitária (ANVISA), que define cosméticos como sendo preparações constituídas por substâncias naturais ou sintéticas, de uso externo nas diversas partes do corpo humano, pele, sistema capilar, unhas, lábios, órgãos genitais externos, dentes e membranas mucosas da cavidade oral, com o objetivo exclusivo ou principal de limpálos, perfumá-los, alterar sua aparência e/ou 
corrigir odores corporais, protegê-los ou mantêlos em bom estado.

Em relação à segunda pergunta, a maioria dos alunos afirmaram fazer uso de cosméticos em seu dia a dia, principalmente as mulheres, citaram exemplos tais como cremes para os cabelos e pele, protetor solar, gel, desodorantes, entre outros. $\mathrm{O}$ que remete ao entendimento que mesmo não tendo o conhecimento exato do significado do termo "cosmético", a maioria deles consegue inferir quais produtos podem ser considerados como tal.

Não obstante, ao serem questionados sobre a função dos cosméticos, terceira pergunta, percebeu-se que os mesmos não tinham um conhecimento tão abrangente sobre o termo, propuseram de forma geral que estes teriam a função de hidratar o corpo, em específico a pele, rosto, braços, mãos e pernas, ou seja, não foram capazes de associar seu uso a diversas outras funções, muito menos órgãos/partes do corpo.

No que se refere à quarta pergunta, na qual os alunos foram indagados sobre se poderiam aprender/estudar conceitos químicos a partir dos cosméticos (Gráfico 2), a maioria dos alunos respondeu que seria possível, $75 \%$, enquanto que o restante, $25 \%$, afirmou que não.

Gráfico 2. É possível aprender conceitos químicos a partir dos cosméticos?

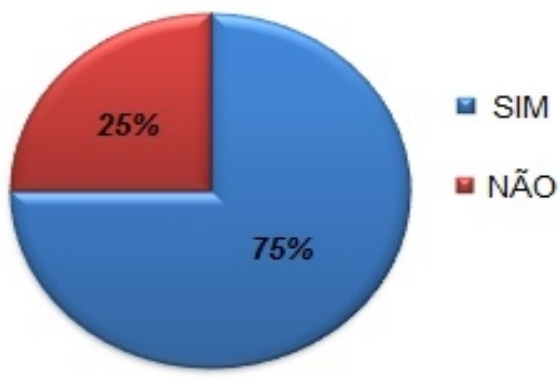

Fonte: Autoria.

Entretanto, dos $75 \%$ que afirmaram que sim, ao serem questionados sobre quais conteúdos e/ou conceitos químicos poderiam ser trabalhados na disciplina de Química, praticamente nenhum deles soube responder, sendo apenas capazes de associar os cosméticos à química orgânica.

A fim de esclarecer as dúvidas dos alunos em relação aos conteúdos/conceitos de química que podem ser trabalhados com o tema cosméticos, foi dito aos mesmos que suas dúvidas seriam melhor esclarecidas no próximo encontro por meio da elucidação das fórmulas estruturais de alguns compostos químicos presentes em alguns cosméticos, deste modo, estimulando a participação dos mesmos e incitando a curiosidade pelo assunto em desenvolvimento.

Em relação à quinta pergunta, sobre a importância dos cosméticos na vida de cada um, todos disseram que estes são bastante importantes, citando exemplos já discutidos anteriormente (segunda pergunta). No que concerne à última pergunta, sobre alergias provenientes de cosméticos, todos disseram que nunca tiveram, e embora a discussão não tenha sido aprofundada, ressaltou-se que vários sãos os casos em que pessoas desenvolvem alergia frente a algum tipo de cosmético.

Com relação às alergias provenientes do uso de cosméticos, foi explicitado aos alunos que essas alergias acontecem devido a reações indesejadas, ou seja, reações que podem ocorrer devido à exposição continuada de um indivíduo a uma determinada substância presente no produto, que não tem uma interação favorável entre algum componente da formulação do cosmético com as proteínas da pele. E que essas alergias podem aparecer em locais distintos e/ou no próprio local de aplicação (GOMES, 2013).

Após as discussões inerentes às perguntas do questionário aplicado, deu-se início à leitura e discussão de dois textos relacionados aos cosméticos, "A história dos cosméticos" e "Química dos cosméticos" (Santos et al. 2013). Ao executarem a leitura dos textos propostos, os alunos ficaram um pouco inibidos, o que permitiu inferir que não possuíam o hábito de ler, sendo então necessário fazer a leitura e explicar cada parágrafo dos textos para que ficasse claro como se deu o surgimento dos cosméticos, composição dos mesmos e os cuidados necessários que se deve ter ao fazer uso desses produtos.

Destaca-se que a leitura em sala de aula se torna uma importante ferramenta para o processo de ensino e aprendizagem e ainda, na formação escolar, pois ler significa refletir, pensar, 
estar a favor ou contra, comentar, trocar opiniões, posicionar-se, enfim, exercer desde cedo a cidadania (COSTA e HILLESHEIM, 2004).

De forma geral, mediante a discussão dos textos os alunos puderam compreender melhor a origem dos cosméticos e sua repercussão na sociedade até os dias atuais. Puderam ainda compreender a influência dos cosméticos em seu contexto social atentando para o cuidado com seu uso.

Além disso, foi possível notar que ao se abordar a história dos cosméticos, fez-se uso de conhecimentos diferentes dos químicos. O que vem ao encontro do exposto por Silveira e Pinto Neto (2008), ao afirmarem que o processo do ensino de ciências deve ser, também, histórico, levando em consideração as produções que foram elaboradas na construção de um determinado conhecimento.

Para finalizar o encontro, ainda pautado no segundo texto trabalhado, enfatizou-se aos alunos algumas maneiras de se utilizar os cosméticos com mais cuidado, pois se sabe que em sua composição química existem componentes que podem ser prejudiciais à saúde. Portanto, foram ressaltados cuidados tais como:

- Atentar-se aos rótulos dos cosméticos consumidos, pois conhecê-los bem pode fazer com que se obtenha melhores resultados na sua utilização;

- Evitar fazer uso de produtos em excesso, principalmente os de higiene pessoal e limpeza;

- Utilizar quantidade pequena de creme dental, pois há risco de se engolir flúor em excesso, o qual é prejudicial.

Diante do exposto, essa atividade final realizada no primeiro encontro foi fundamental para a contextualização da temática que estava sendo abordada, pois além de apresentar brevemente sua relação com a química orgânica, ponto esse apresentado e discutido no segundo encontro, ainda proporcionou aos alunos compreender alguns cuidados necessários quanto à utilização dos cosméticos.

Nessa perspectiva, Santos (2007) ressalta que, a aprendizagem por meio da contextualização envolve a vinculação de temas sociais e situações reais aos conteúdos, possibilitando a discussão transversal dos conteúdos com os conceitos científicos, permitindo assim aos alunos a compreensão do contexto social em que estão inseridos desenvolvendo a capacidade da tomada de decisões.

\subsection{Segundo Encontro}

O segundo encontro (Organização do conhecimento) iniciou-se com a discussão e explanação das principais funções orgânicas, mediante uso da Tabela 1, que posteriormente seriam estudadas utilizando-se as fórmulas estruturais das substâncias presentes nos cosméticos que seriam trabalhados em sala, tais como: pasta de dente, perfume, xampu, protetor solar e sabonete.

Sequencialmente ao estudo e discussão dos procedimentos acerca de como identificar as funções orgânicas, aos alunos foram apresentadas algumas das principais substâncias orgânicas presentes em vários tipos de cosméticos utilizados cotidianamente por eles, assim como suas funções químicas na fabricação desses produtos, tais como conservante, adoçante, aromatizante e umectante.

Em relação à pasta de dente, apresentouse a fórmula estrutural do sorbitol, para o perfume o eugenol, para o xampu o parabeno, para o protetor solar o ácido aminobenzóico e para o sabonete o butifenil-metilpropional.

Após a apresentação, elucidação e discussão dos cosméticos e suas principais substâncias constituintes, aos alunos foi solicitado que identificassem as funções orgânicas presentes em cada uma das substâncias mencionadas (Aplicação do conhecimento). Tais produtos, substâncias e funções químicas seguem ilustradas na Tabela 2.

Tendo como base as fórmulas estruturais, a primeira função a ser trabalhada foi a presente na fórmula estrutural do sorbitol, a função álcool. Nesse sentido, ao serem indagados sobre qual(is) função(ões) estava(m) presente(s) na estrutura do referido composto, após algum tempo e analisando a tabela proposta inicialmente, os alunos disseram ser a função álcool.

Em seguida, perguntou-se se eles sabiam definir as características dessa função, como respostas obtidas, de maneira geral afirmaram que a mesma é característica da presença do 
grupo - $\mathrm{OH}$ (hidroxila), além da nomenclatura com terminação ol. Entretanto, tal definição foi complementada aos alunos ao relatar aos mesmos que a inferência da função álcool não se limita apenas às suas características descritas anteriormente.

Deste modo, relatou-se que para que uma função seja realmente um álcool, o grupo $-\mathrm{OH}$ também deve estar ligado a um carbono saturado, caso contrário, dependendo da estrutura, poderia ser classificado como um fenol, o qual foi brevemente elucidado na lousa.

As diferenças entre os grupos funcionais, álcool e fenol, ainda foram rapidamente salientadas, ressaltando-se que nos álcoois a hidroxila encontra-se ligada a átomos de carbono saturados, isto é, que apresentam somente ligações simples.

Em relação aos fenóis, a característica estrutural que os define é a ligação da hidroxila a um anel aromático, além destas diferenças, ressaltou-se rapidamente sobre a existência da função enol, que também foi desenhada na lousa e brevemente explicada, dessa forma assegurando um melhor entendimento dos alunos.

Após discorrer-se sobre as funções álcool, fenol e enol, foi apresentado aos alunos a fórmula estrutural do eugenol, substância encontrada em perfumes, e solicitado aos mesmos que identificassem os grupos funcionais contemplados neste composto.

Com base nas explicações anteriores, os alunos facilmente disseram que havia na estrutura o grupo fenol, contudo, não conseguiram identificar com clareza o grupo éter, devido ao fato do oxigênio e do anel aromático estar ligado ao grupamento metila sem elucidação da ligação simples entre eles $\left(\mathrm{CH}_{3}-\right.$ $\mathrm{O}-\mathrm{Ph}$ ), o que foi facilmente compreendido após algumas explicações sobre as formas como o mesmo pode ser identificado.

Ainda, com a intensão de contextualizar um pouco mais a aula, foi explicitado aos alunos que dentre vários óleos essenciais extraídos do cravo-da-índia, o eugenol é o principal deles, sendo este, um composto fenólico muito utilizado na fabricação de perfumes e medicamentos (RODRIGUES, 2010).
Os procedimentos, análises e discussões para a identificação das funções orgânicas presentes nas demais substâncias representadas por suas fórmulas estruturais (parabeno, ácido aminobenzóico e butifenil metilpropional) deramse da mesma maneira como realizado para o sorbitol e o eugenol.

Ao término da identificação de todas as funções orgânicas de todas as substâncias, fezse aplicação de uma lista de atividades que contemplava o mesmo conteúdo trabalhado, tendo esta, a finalidade de verificar se os alunos haviam aprendido efetivamente os conceitos abordados.

Apesar de algumas dificuldades ainda encontradas por alguns alunos na identificação dos grupos funcionais, estas foram, aos poucos, sendo reduzidas no desenvolver da realização e resolução da atividade proposta.

\section{CONCLUSÕES}

A realização do minicurso possibilitou oportunidade para os alunos de relacionarem a Química com seu cotidiano, visto que o aprendizado não deve estar restrito apenas ao que se aborda na sala de aula. Sendo possível mostrar a importância de se estudar química e como esta ciência pode ser relacionada à suas vidas por meio da compreensão acerca de suas implicações práticas, neste caso, sua relação com a produção e uso dos cosméticos.

As aulas do minicurso proporcionaram aos alunos obterem o conhecimento químico, a partir dos cosméticos, visto que tiveram a total liberdade de dar opiniões, havendo assim, uma maior participação, tendo estes a autonomia de expressarem o que pensam, reconstruir e reelaborar o conhecimento que já possuíam. Fato que pôde ser verificado ao se discutir, por exemplo, as indagações propostas no questionário aplicado na primeira aula. Sendo, possível, portanto, tornar a Química parte de sua vivência.

Destaca-se também que o desenvolvimento da referida abordagem não tratou apenas de conceitos e conteúdos químicos, como também corroborou para a importância de se discutir temáticas sociais e históricas através do incentivo à criação de um ambiente de leitura e reflexão, estratégias utilizadas majoritariamente pelas Ciências 
Humanas, mas, que precisam ser adotadas por todas as áreas do conhecimento, ao passo que, como constatado no trabalho, muitos alunos não apresentam o hábito da leitura.

Ademais, pautado nas concepções prévias dos alunos provenientes do primeiro encontro e nos resultados inferidos a partir da aplicação e resolução da última atividade proposta, concluise que a referida abordagem proporcionou aos alunos um aprendizado efetivo no que se refere aos conceitos básicos relacionados às funções orgânicas, principalmente no que se refere às funções álcool e fenol.

Por fim, pôde-se verificar que a utilização dos cosméticos como tema gerador de conhecimento químico mostrou-se uma estratégia promissora para contextualização com vistas a melhores resultados da aprendizagem, no tange ao conteúdo de funções orgânicas, contribuindo não apenas para o desenvolvimento do conhecimento científico, mas também, para a aprendizagem de diversos aspectos, como sociais e históricos. Acarretando assim, em um ensino de Química comprometido com a construção da cidadania e despertando no aluno um interesse e incentivo pela disciplina.

\section{AGRADECIMENTOS:}

Ao Núcleo de Pesquisa e Extensão em Processos Educacionais - NUPEPE.

Ao Núcleo de Pesquisa e Estudos em Química de Goiás - NUPEQUI.

Aos Alunos do curso Técnico Integrado em Química.

Ao Instituto Federal de Educação, Ciência e Tecnologia de Goiás - IFG campus Itumbiara$\mathrm{GO}$.

\section{REFERÊNCIAS}

1. Barata, E. A. F. A Cosmetologia: Princípios Básicos. São Paulo: Tecnopress, 1995. 176p.

2. Bennett, J. e Holman, J. Context-based approaches to the teaching of chemistry: what are they and what are their effects? In J. Gilbert (Ed.), Chemical education research-based practice. Dordrecht, The Netherlands: Kluwer Academic Publishers, 2002.

3. Brasil. Ministério da Educação. Secretaria de Educação Média e Tecnológica. Parâmetros curriculares nacionais: ensino médio. Brasília: MEC/SEMTEC, 1999. 4v.

4. Brasil. Orientações Curriculares para o Ensino Médio: Ciências da natureza, matemática e suas tecnologias. Brasília: Ministério de Educação Média e Tecnológica, 2006.

5. Chaer, G.; Diniz, R. R. P.; Ribeiro, E. A.A Técnica do Questionário na Pesquisa Educacional. Evidência (Araxá), v. 7, p. 251-266, 2011.

6. Costa, A. L.; Hillesheim,A. L. A. Atividades de incentivo à leitura na Escola Básica Padre João Alfredo Rohr. s/d. Disponível em:

<http://www.extensio.ufsc.br/20041/artigo s_pdfs/CED_Araci.pdf $>$. Acessado em julho 2015.

7. Delizoicov, D.; Angotti, J. A. P. Metodologia do ensino de ciências. São Paulo: Cortez, 1990. (Coleção magistério. $\quad 2^{\circ}$ grau. Série formação do professor).

8. Gilbert, J. K. On the Nature of "Context" in Chemical Education. Int. J. Sci. Educ. 2006, 28, 957-976.

9. Gomes, A. B. Alergia a cosméticos. Ativos Dermatológicos: São Paulo, 2013.

10. Gomes, F.; Machado, F. S.; Costa, L. L.; Alves, B. H. P. Atividades DidáticoPedagógicas para o Ensino de Química Desenvolvidas pelo Projeto PIBID-IFG. Quím. Nova na Escola, Vol. 36, $\mathrm{N}^{\circ} 3$, p. 211-219, 2014.

11. Morillo, F.; Bordons, M.; Gómez, Isabel. Interdisciplinarity in Science: A Tentative Typology of Disciplines and Research Areas. J. Am. Soc. Inf. Sci. Technol., 54 (13):1237-1249, 2003.

12. Rodrigues, R. S.; Silva, R. R. A História sob o Olhar da Química: As Especiarias e sua Importância na Alimentação Humana. Quím. Nova na Escola, v. 32, n.2, 2010.

13. Sá, H. C. A.; Silva, R. R. Contextualização e interdisciplinaridade: concepções de professores no ensino de gases. <http://www.quimica.ufpr.br/eduquim/eneq 2008/resumos/R0621-1.pdf>. Acessado em novembro 2015.

14. Santos, W. L. P. Contextualização no Ensino de Ciências por meio de Temas CTS em uma perspectiva crítica. Ciência \& Ensino, v.1, n. especial, Nov.2007. 
15. Santos, W. L. P.; Mól, G. S.; Dib, S. M. F.; Matsunaga, R. T.; Santos, S. M. O.; Castro, E. N. F.; Silva, G. S.; Farias, S. B. Química cidadã: volume 3, ensino médio $3^{\circ}$ série. 2. ed. São Paulo: Editora AJS, 2013. v. 1. 320p

16. Santos, W. L. P.; Mól, G. S.; Silva, R. R.; Castro, E. N. F.; Silva, G. S.; Matsunaga, R. T.; Farias, S. B.; Santos, S. M. O.; DIB, S. M. F. Química e Sociedade: uma experiência de abordagem temática para o desenvolvimento de atitudes e valores. Quím. Nova na Escola, Brasil, v. 20, p. 1114, 2004.

17. Scarpa, D. L.; Maximiano, F. A.; Oliveira, H. A.; Fonseca, L. C. S.; Camargo, S.; Roehrig, S. A. G. Formação de professores do ensino médio, etapa II Caderno III: Ciências da Natureza. 1. ed. UFPR: setor de educação, v.1.: Curitiba, 2014.

18. Schueller, R.; Romanowski, P. Iniciação à Química Cosmética. v. 1. São Paulo:
Tecnopress, 2001.

19. Silva, M. R.; Simões, C. A.. O currículo do ensino médio, seu sujeito e o desafio da formação humana integral. Curitiba PR: Setor de Educação/UFPR, 2013.

20. Silva, R. M. G.; Contextualizando aprendizagens em Química na formação escolar. Quím. Nova na Escola, São Paulo, v. 1, n.18, p. 26-30, 2003.

21. Silveira, H. E. Pinto Neto, P. C. O desenvolvimento de conceitos químicos em artigos de história da ciência: possibilidades de novas abordagens para formação docente. In: Encontro Nacional de Ensino de Química, XIV, 2008, Paraná, Curitiba, 2008, p.1-8.

22. Stuckey M.; Hofstein A.; Mamlok-Naaman $\mathrm{R}$. and Eilks I. The meaning of 'relevance' in science education and its implications for the science curriculum, Stud. Sci., Educ., 2013, 49(1), 1-34

23. Usberco, J.; Salvador, E. Química. 5 ed. São Paulo: Editora Saraiva, 2002. 
Tabela 1. Representação das principais funções orgânicas trabalhadas em sala.

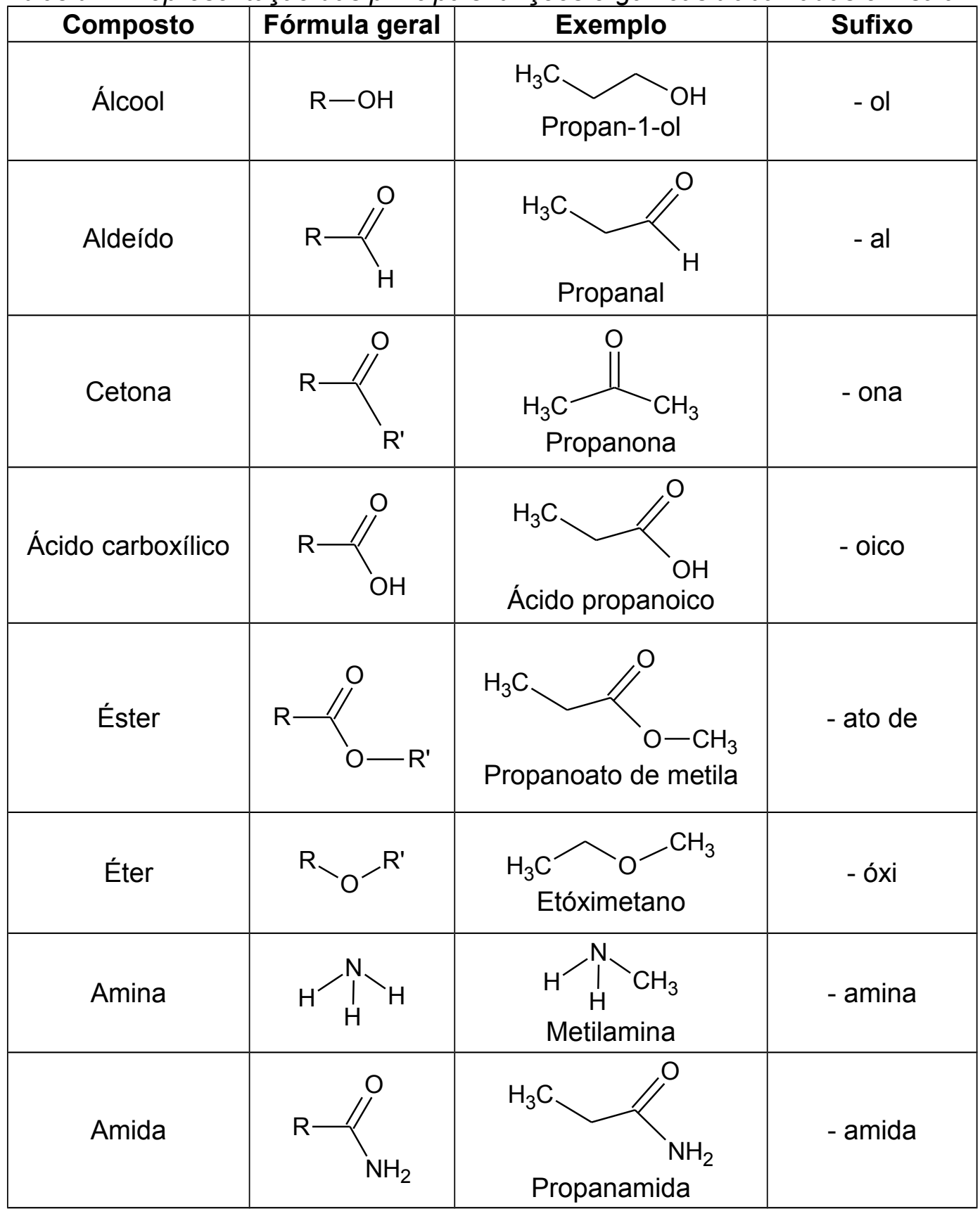

Fonte: Autoria 
Tabela 2. Cosméticos e seus respectivos compostos orgânicos.

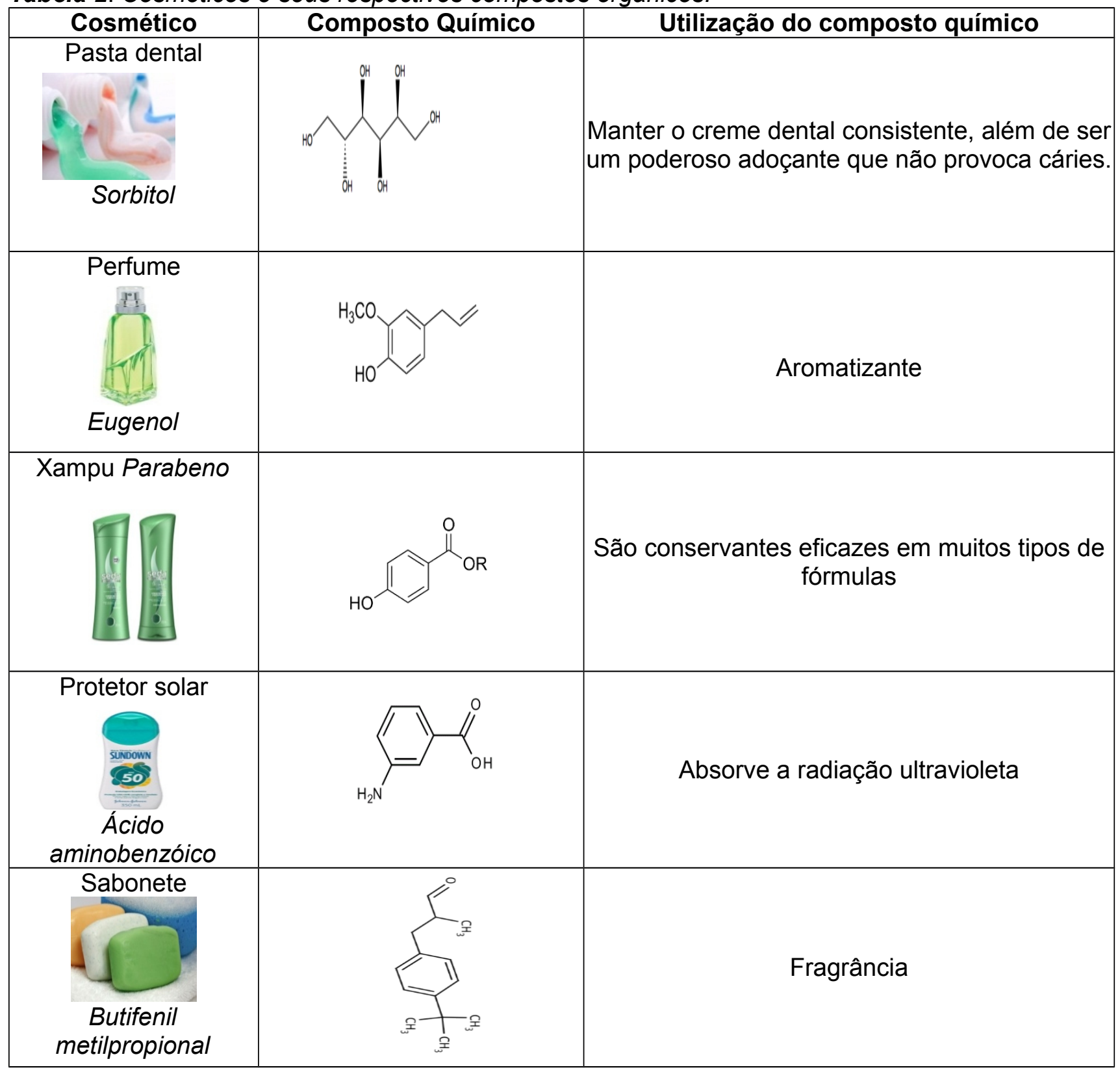

Fonte: Autoria.

PERIÓDICO TCHÊ QUÍMICA • www.periodico.tchequimica.com • Vol. 6 N. 12.

- ISSN 1806-0374 (impresso) • ISSN 1806-9827 (CD-ROM) • ISSN 2179-0302 (meio eletrônico)

(C) 2010. Porto Alegre, RS. Brasil

The Periódico Tchê Química (ISSN: 1806-0374; 2179-0302) is an open-access journal since 2004. Journal DOI: 10.52571/PTQ. http://www.tchequimica.com. This text was introduced in this file in 2021 for compliance reasons.

OPEN ACCESS. This article is licensed under a Creative Commons Attribution 4.0 (CC BY 4.0) International License, which permits use, sharing, adaptation, distribution, and reproduction in any medium or format, as long as you give appropriate credit to the original author(s) and the source, provide a link to the Creative Commons license, and indicate if changes were made. The images or other third-party material in this article are included in the 